\title{
SUPLEMENTAÇÃO ALIMENTAR NAS UNIDADES DE SAÚDE DO MUNICÍPIO DE RIBEIRÃO PRETO
}

\author{
SUPPLEMENTARY FOOD PROGRAMME IN THE PUBLIC HEALTH SERVICES OF RIBEIRÃO PRETO CITY
}

\author{
Sônia C. Sant'Anaํ \& Semíramis M. de M. Rocha²
}

\begin{abstract}
Enfermeira do Centro de Saúde Escola de Ribeirão Preto, mestre em Saúde Pública ${ }^{1}$. Docente da Escola de Enfermagem de Ribeirão Preto da Universidade de São Paulo?.

CoRRESPONDÊNCIA: Sônia Camila Sant'Ana. Rua Itapura, № 15, Edifício Bologna, apto 24, Jardim Paulista - CEP: $14090-080$ - Ribeirão Preto - SP - Fone: 624-9204.
\end{abstract}

SANT'ANA SC \& ROCHA SM de M. Suplementação alimentar nas unidades básicas de saúde do município de Ribeirão Preto. Medicina, Ribeirão Preto, 30: 272-276, abr./jun. 1997.

RESUMO: Esta investigação consistiu em estudar o Programa de Suplementação Alimentar, destinado a menores de cinco anos, nos serviços de saúde da rede pública do município de Ribeirão Preto. Tomando as práticas em saúde como trabalho, apreendemos como era realizado o programa, através das relações entre clientela e agentes do processo de trabalho. Os dados empíricos foram as falas e atitudes dos sujeitos envolvidos, coletados por entrevista e observação direta, e os documentos oficiais. A análise constituiu do confronto dos dados com os aspectos da observação selecionados para análise: ambiente, dinâmica e embasamento teórico para o atendimento e o confronto dos dados entre si. $O$ estudo demonstrou discrepâncias entre a concepção teórica e a operacionalização do programa. O ambiente apresentava inadequações, a rotina reduzida à entrega e controle dos tíquetes, as relações entre os agentes e a clientela foram impessoais, permeadas por conflitos relacionados à contenção da demanda. A criança fica à margem desse atendimento. As instâncias centrais não se articulavam com as unidades básicas, quando estabeleciam uma linha de continuidade da proposta à execução do programa. Entendemos oportuna uma reorganização, quanto ao diagnóstico da desnutrição, em cada realidade, com a participação dos agentes e clientes na elaboração das estratégias de intervenção.

UNITERMOS: Suplementação Alimentar. Programas de Nutrição. Criança.

\section{INTRODUÇÃO}

A desnutrição protéico-calórica, em crianças menores de cinco anos, é o mais grave problema de nutrição enfrentado no mundo e no Brasil ${ }^{1,2}$, e a responsabilidade do diagnóstico e a intervenção neste grupo foi atribuída ao setor saúde, desde $1970^{3,4}$.

Assim, o Programa de Suplementação Alimentar (PISA) foi inserido na Secretaria de Estado da Saúde de São Paulo, destinado a menores de cinco anos, e passou por várias fases de operacionalização, acompanhando os diferentes modelos das políticas de saúde de 1970 até 1993.

$\mathrm{Na}$ literatura consultada, vários estudos registram avaliações sobre o resultado dessas intervenções na queda da desnutrição grave e nas taxas de morbimortalidade infantil ${ }^{3,4}$.

Nosso interesse, entretanto, centralizou-se nas práticas de saúde voltadas para a criança, clareando como a mesma era percebida no interior do atendimento nos serviços de saúde.

Desta forma, em nossa dissertação de mestrado, estudamos a configuração da prática do PISA, na rede 
básica de saúde do Município de Ribeirão Preto, delineando as ações com vistas a implementá-las. Pretendemos, neste breve relato, divulgar o resultado de nossa investigação.

Concernente aos objetivos específicos da pesquisa, analisamos a realização do PISA no município de Ribeirão Preto, nas unidades básicas de saúde, e as relações dos agentes do processo de trabalho em saúde com a clientela, dentro das ações de promoção nutricional propostas pelo programa.

Tomando as práticas de saúde como um trabalho, fundamentamos nossa análise em MENDES GONÇALVES $^{5}$ e ROCHA ${ }^{6}$. Desenvolvemos um estudo de natureza qualitativa, procurando compreender o processo saúde-doença na sua totalidade social.

Nesta abordagem, não se cuidou de avaliação em termos de eficácia e eficiência, mas de configurar as relações entre os atores sociais participantes desta assistência, ou seja, agentes do processo de trabalho em saúde e a clientela. E não houve a preocupação com inferências à população geral, mas em conhecer o mais profundamente uma realidade concreta.

Logo, procuramos conhecer como se processava a suplementação alimentar inserida na prática de assistência à saúde da criança, a nível de atenção primária, mediante a observação do ambiente, instrumentos, agentes e clientela. Os dados empíricos foram as falas e atitudes dos sujeitos envolvidos, coletados através de entrevista e da observação direta e a análise dos documentos oficiais.

Utilizamos, também, como referencial teórico-metodológico, na elaboração dos instrumentos de coleta de dados, a análise MINAYO ${ }^{7}$ e TRIVIÑOS $^{8}$. Segundo esses autores, através das entrevistas semi-estruturadas, podemos obter dados concretos (os quantitativos) e dados subjetivos (que se referem a opinião dos sujeitos) e, com a observação direta, podemos recortar um fenômeno social de seu contexto, e estudar seus atos, atividades e significados.

Elegemos os seguintes documentos oficiais como balizadores da análise: BRASIL $1984^{9}$, SÃO PAULO $1989^{10}$ e RIBEIRÃO PRETO $1991^{11}$.

A investigação iniciou-se nas instâncias centrais das Secretarias Estaduais e Municipais, com as entrevistas, até as unidades básicas de saúde, quando realizamos a observação do atendimento, foco central deste estudo. Escolhemos um Distrito cuja configuração, em janeiro de 1993, contava com quatro unidades. No sentido de melhor compreendermos o atendimento do SISVAN/PISA, realizado nas unidades observadas, selecionamos os seguintes aspectos da nossa observação para análise: ambiente do atendimento, dinâmica do atendimento e embasamento teórico dos agentes de trabalho para o atendimento.

No que diz respeito ao ambiente, voltamos nossa atenção às condições higiênicas, à ventilação, à iluminação, aos mobiliário e aos materiais do espaço onde se processa o atendimento. Em termos de dinâmica, pontuamos como importante a relação entre o auxiliar e a mãe (ou acompanhante) e a criança, a rotina do atendimento e o tempo empregado para $\mathrm{o}$ atendimento.

Com referência ao embasamento teórico, levamos em conta as informações transmitidas pelo auxiliar, durante o atendimento, relativas à higiene, à alimentação, ao crescimento, ao desenvolvimento e à puericultura. Para a análise desses aspectos, detivemo-nos em três esquemas: confronto entre as observações, em cada unidade, em relação aos aspectos selecionados para análise, confronto entre os documentos oficiais, confronto entre observação e documentos.

Empenhamo-nos, ao longo do processo, em contemplar outros aspectos que ultrapassassem nossa classificação inicial, desde que fornecessem elementos à compreensão de nosso objeto de investigação. Procuramos integrar as conclusões à luz da fundamentação teórica, refletindo sobre as relações entre a prática do atendimento e o discurso oficial sobre o Programa de Suplementação Alimentar, finalizando a síntese, ou seja, os resultados.

\section{O PISA EM RIBEIRÃO PRETO}

Em Ribeirão Preto, em 1993, o Programa de Suplementação Alimentar (PISA) estava vinculado ao Programa de Assistência à Criança, segundo as normas técnicas da Secretaria de Estado da Saúde de São Paulo $^{10}$. Como o processo de municipalização se estruturava no município de Ribeirão Preto, a Secretaria de Saúde do Estado, representada pelo ERSA-50, centralizava o controle da orientação e operacionalização das normas padronizadas pela SES/SP para o PISA/SISVAN, realizava o levantamento do número de crianças beneficiárias, encarregava-se da compra do suplemento (leite das Cooperativas e Laticínios), confeccionava os tíquetes (vales de leite) e os entregava ao Setor Administrativo da Secretaria Municipal de Saúde para a distribuição nos distritos.

Os distritos sanitários eram autônomos na distribuição da cota por UBS, mas o ERSA-50 tinha o controle da cota destinada ao município. 
No relatório de despesas do ERSA-50, do ano de 1992 , o programa representava cerca de $50 \%$ das despesas totais realizadas naquele ano. Classificando-o como oneroso, alegaram não haver um sistema de avaliação indicando o impacto do programa na comunidade, para justificar tal investimento. Atribuíam ao processo de municipalização a falta de informações do nível local.

Detectamos, porém, que o PISA/SISVAN era um programa estruturado, desde 1984, com impressos e boletins de controle desde sua implantação; desta forma, o nível central deveria dispor de informação anteriores; ainda inúmeros trabalhos científicos sobre o impacto desta intervenção foram realizados, todavia este conhecimento não foi utilizado. Assim, a preocupação com o controle dos gastos superava o combate à desnutrição.

A partir das informações coletadas no ERSA-50, passamos ao nível central de Secretaria Municipal da Saúde (SMS). Neste órgão, as áreas responsáveis pela operacionalização técnica do programa eram o Programa de Educação Contínua (PEC) e o setor administrativo. Este último realizava a transferência dos tíquetes recebidos do ERSA para os Distritos.

O Programa de Educação Contínua (PEC) era responsável em promover os treinamentos e reciclagens de pessoal, operacionalizar programas nas unidades básicas, sendo o pessoal auxiliar de enfermagem quem executava o atendimento à criança e distribuía os tíquetes, ficando a enfermeira com a supervisão técnica do seu trabalho. Era nossa expectativa que os enfermeiros participassem dessa atividade.

O PEC preocupava-se com o controle e as ações de promoção em saúde preconizadas pelo PISA, percebiam limitações das unidades em realizá-las, estabeleciam contacto com as mesmas, contudo não avançavam no sentido de instrumentalizar o atendimento.

Comentaram, também, a necessidade do controle do programa: para tanto, elaboravam um boletim específico para a Secretaria Municipal de Saúde que estava em fase de implantação, no momento da coleta de dados.

Entre o ERSA-50 e a SMS, não havia um fio condutor das informações, nem cooperação mesmo dentro de cada órgão, o trabalho era desarticulado no segundo estágio de descentralização do programa. As cotas de leite, controladas pelo Setor de Patrimônio, no ERSA, eram distribuídas pelo Setor Administrativo, na SMS, sem contato com os responsáveis pela operacionalização técnica. Os setores técnicos do
ERSA e da SMS também atuavam sem articulação, os treinamentos realizados pelo ERSA eram dissociados dos treinamentos dos profissionais da SMS, que atuavam a nível local com as orientações parcializadas, sem retaguarda técnica.

Continuando, percorremos as unidades do distrito selecionado; chegando ao último estágio de descentralização, nos detivemos na observação do atendimento de enfermagem prestado à criança matriculada no programa.

Quanto ao ambiente, os documentos e normas oficiais referentes ao Programa de Suplementação Alimentar não mencionam especificações para as instalações. Logo, não obtivemos elementos para o confronto entre o preconizado e o observado; entretanto, utilizamos as normas técnicas do Ministério da Saúde, que tratam da padronização das instalações dos serviços de saúde, BRASIL, 1979 e $1985^{12,13}$ para uma apreciação. Verificamos espaços exíguos, locais de difícil acesso, e várias atividades realizadas simultaneamente colocavam usuários e profissionais aglomerados, prejudicando a qualidade do atendimento. Assim, a jornada de trabalho era exaustiva, influindo no seu rendimento e dificultando a execução da atividade. A clientela era atendida em local sem privacidade e com desatenção.

Os instrumentos mínimos, balanças e antropômetros, ou estavam ausentes ou, quando presentes, eram inadequados; verificamos réguas e antropômetros quebrados. As técnicas antropométricas, executadas de forma errada, portanto, o diagnóstico da desnutrição estava comprometido. O uso de prontuário, gráficos, cartão de retorno, cartão de vacinas não era uniforme a todas as unidades, o que evidenciava um hiato na história de crescimento e desenvolvimento da criança.

Quanto à dinâmica do atendimento, quando era sistematização em pesar, medir, registrar em prontuário e verificar a carteira de vacinas, como descrita nos documentos oficiais, era efetuada de forma mecânica e desarticulada, os dados não revertiam em instrumentos de orientação às mães sobre suas crianças, o tempo do atendimento era de um a dois minutos por criança. A relação estabelecida entre clientes e agentes do processo de trabalho, embora não explicitada nas normas técnicas, seria de importância singular para o desenvolvimento do programa. Desta forma, apesar de não normatizada, a rotina de procedimentos exigiria uma duração maior. Verificamos que estas relações foram impessoais, reduzidas a simples entrega dos tíquetes. 
Observamos, aqui, uma contradição, pois, atribui-se ao programa o acompanhamento do crescimento e desenvolvimento e o controle da desnutrição; logo, a promoção deveria atrair as mães e as crianças para os serviços, durante este atendimento. Entretanto, pudemos detectar que, dentre as ações realizadas nas unidades básicas, o programa era executado por um auxiliar de enfermagem com várias atribuições, dedicando, no máximo, $30 \%$ de sua jornada para esta tarefa.

À criança, centro das atenções, nas normas técnicas e na prática, privilegiaram controlar a distribuição dos tíquetes, de forma mecânica.

Quanto ao embasamento teórico, as técnicas antropométricas, os conhecimentos básicos sobre nutrição, puericultura e higiene da criança, noções de crescimento e desenvolvimento constituíam o embasamento teórico mínimo, contidas nas normatizações dos critérios de inscrição e alta: normas técnicas (n. 32/85 e n. 33/85; n. 47/89 e n.48/89) ${ }^{10}$.

Os dados expostos revelaram as discrepâncias de um programa com amplos objetivos em sua premissa e precária operacionalização técnica do pessoal responsável pelo atendimento das crianças.

Se os auxiliares tinham o embasamento necessário, não foi possível detectar, pois, não o utilizaram; a atividade ficou reduzida ao ato mecânico de pesar, medir e entregar os tíquetes; despendiam grande parte do tempo com a clientela para preencher os mapa e boletins de controle; esses impressos deveriam consolidar informações sobre a desnutrição na coletividade, subsidiando o trabalho do nível central, a compra do suplemento e avaliações.

As entrevistas realizadas no nível central evidenciaram que estes boletins não eram utilizados, não estabelecendo a integração das informações entre os vários níveis de execução do programa.

\section{CONSIDERAÇÕES FINAIS}

Os técnicos das instâncias federais, estaduais e municipais assumiam a tarefa de redução das taxas de desnutrição, entretanto, a delegavam ao último estágio de descentralização do programa a incumbência de operacionalizá-la segundo normatizações racionalizadoras.

As normas e manuais técnicos, prescrições gerais ficaram supervalorizadas, resultando em uma atenção parcializada, retirando a visão da criança na sua totalidade. A assistência à criança ficou desviada para o rigoroso controle dos tíquetes.

Ao nosso ver, o resultado desta investigação deve ser divulgado como um alerta a todos os técnicos responsáveis por organização de serviços. Acreditamos que o problema nutricional deverá ser repensado em cada realidade, instrumentalizando os agentes de conhecimento técnico e político sobre as determinações da desnutrição na comunidade.

SANT'ANA SC \& ROCHA SM de M. Supplementary food programme in the public health services of Ribeirão Preto city. Medicina, Ribeirão Preto, 30: 272-276, apr./june 1997.

ABSTRACT: This investigation consisted in studying the Programme of Food Supplementation destined to under five years old children in the Public Health Services of Ribeirão Preto. Taking the health pratices as a working process, we learned how it was done and the relation happened among social actors of process (clientele and the working process agents). The empirical data were the speaches and attitudes of the subjects involved, collected by interviews and observation, and official documents. The analysis consisted of the confrontation of the data with the aspects selected: enviromental observation, dynamics and theorical foundation for the attendance and the confrontation of the data among themselves. The study showed discrepancies between the theorical conception and the programme's operational. The enviroment presented inadequacies, the routine reduced to delivery of tickets, the relations between the agents and clientele were impersonal, intervened by conflicts related to the restraint the demand. The child is left aside by this attendance. The central offices didn't articulate with the basic health units to establish a continuity of the proposition for the programme executation. We understand it to be opportune a reorganization as to the diagnosis of malnutrition in each reality, with participation of agents and clients of intervention strategies.

UNITERMS: Supplemntary Feeding. Nutrition Programmes Child. 


\section{REFERÊNCIAS BIBLIOGRÁFICAS}

1 - UNICEF. (Fundo das Nações Unidas para a Infância). Estratégia para melhorar a nutrição de crianças e muIheres nos países em desenvolvimento. New York,1990. n. 1. jun. 38p.

2 - MONTEIRO CA. Saúde e nutrição das crianças de São Paulo: diagnóstico, contrastes sociais e tendências. HUCITEC, São Paulo, 1988. 165p.

3 - PHILLIPI ST. Contribuição ao estudo da suplementação alimentação como atividade de nutrição em programas de saúde: análise de uma experiência na Secretaria de Estado da Saúde de São Paulo. Dissertação de Mestrado. Faculdade de Saúde Pública da USP. São Paulo,1982.

4 - MURAHOVSCHI J et al. Avaliação nutricional de crianças inscritas em um programa de suplementação alimentar (leite fluido). Rev Paul Pediatr 29: 51-54, 1990.

5 - MENDES GONÇALVES RB. Medicina e história. Raízes sociais do trabalho médico. Dissertação de Mestrado. Faculdade de Medicina da USP. São Paulo, p. 1-203, 1979.

6 - ROCHA SM de M. Puericultura e enfermagem. Cortez, São Paulo, 1987.
7 - MINAYO MCS. O desafio do conhecimento. Metodologia da pesquisa social (Qualitativa) em saúde. HUCITEC/ ABRASCO, São Paulo/Rio de Janeiro, 1992.

8 - TRIVINÕS AN. Introdução à pesquisa em ciências sociais: a pesquisa qualitativa em educação. Atlas, São Paulo, 1992.

9 - BRASIL. Ministério da Saúde. Acompanhante do crescimento e desenvolvimento: Ações Básicas na Assistência Integral à Saúde da Criança. Brasília. 1984.

10 - SÃO PAULO (Estado). Secretaria de Saúde. Sistema de Vigilância Nutricional e Alimentar (SISVAN) e Programa Integrado de Suplementação Alimentar (PISA). Diário Oficial do Estado, 1989. Seção 1, p. 7.

11 - RIBEIRÃO PRETO (Cidade). Secretaria Municipal da Saúde. Norma Técnica de acompanhamento e desenvolvimento. Resolução SS-S7, 07 marc. 1991. Seção A.1, p. 19-20.

12 - BRASIL Ministério da Saúde. Divisão Nacional de Organizações de Serviços de Saúde. Normas e padrões de construções e instalações de serviços de saúde. Brasília, 1979. $88 \mathrm{p}$.

13 - BRASIL Ministério da Saúde. Instrumento de avaliação para centros e postos de saúde. Brasília. Centro de Documentação do Ministério da Saúde. 1985. 80p. (Normas e manuais técnicos; série $A$, n. 19). 